\title{
Expression pattern analysis of three R2R3-MYB transcription factors for the production of anthocyanin in different vegetative stages of Arabidopsis leaves
}

\author{
Yeonjong $\mathrm{KoO}^{1^{*}}$ (I) and R. Scott Poethig ${ }^{2}$
}

\begin{abstract}
Anthocyanin is a type of flavonoid that appears purple in plants. PAP1, PAP2, and MYB113 are the three major R2R3MYB transcription factors that regulate flavonoid biosynthesis in Arabidopsis thaliana. In this study, we found that the three MYB genes regulate anthocyanin accumulation in different leaf stages. Under limited nutrient conditions, PAP1 and PAP2 genes were highly induced in juvenile leaves. Conversely, MYB113 was expressed mainly in adult leaves. In addition, we investigated the role of trans-acting siRNA4 (TAS4) in the post-transcriptional regulation of anthocyanin expression in Arabidopsis leaves. In plant growth, the inhibition of PAP1 and PAP2 gene expression by TAS4 was observed only in juvenile leaves, and MYB113 inhibition was observed in adult leaves. In conclusion, we found that transcription and transcript repression of the three MYB genes is differentially regulated by TAS4 in leaf developmental stages. Our results improve the understanding of the regulation of plant anthocyanin production under stress conditions.
\end{abstract}

Keywords: Anthocyanin, R2R3-MYB, Trans-acting siRNA4, Arabidopsis

\section{Introduction}

Chlorophyll, carotenoids, and flavonoids are unique pigments responsible for the various colors found in plants. Anthocyanins are a group of flavonoids that can appear red, blue or purple in flowers, fruits, and leaves. The major role of anthocyanins in plants is to protect cells from ultraviolet light $[1,2]$, scavenge reactive oxygen species $[3,4]$, transport auxin [5, 6], and attract pollinators using petal colors [7]. The synthetic mechanisms, biosynthetic enzymes, and regulatory factors of anthocyanins have been studied intensively in the last three decades because flavonoids are a good candidate for dietary antioxidant and anti-inflammatory materials $[6,8,9]$.

\footnotetext{
*Correspondence: yeonjong@jnu.ac.kr

${ }^{1}$ Department of Agricultural Chemistry, Chonnam National University,

Gwangju 61186, South Korea

Full list of author information is available at the end of the article
}

Anthocyanin synthesis is induced by abiotic stress, such as nitrogen or phosphate starvation, high sucrose levels, or cold [10-15]. Biosynthetic enzymes from flavonoid pigments have been isolated in various plants, including Arabidopsis, maize, petunias, and snapdragons [16-18]. Biosynthetic pathways are classified as early biosynthetic genes from chalcone synthase to flavonoid 3'-hydroxylase and late biosynthetic genes from dihydroxy flavonoid reductase to anthocyanidin synthase (ANS) [19-26]. The expression of these flavonoid biosynthetic enzymes is regulated by the transcriptional complex, WD-repeat/ MYB/bHLH [27]. MYB transcription factors are sufficient and are limiting factors for anthocyanin synthesis in Arabidopsis. The Arabidopsis pap1-D mutant displays purple colors [28] and the transgenic plants with R2R3MYB (PAP1, PAP2, MYB113, and MYB114) gene overexpression display enhanced anthocyanin synthesis [26, 28-30]. Anthocyanin accumulation in plants generally 
correlates with R2R3-MYB transcription factor expression in Arabidopsis.

Trans-acting siRNA 4 (tasiRNA4, TAS4) and microRNA828 (miR828) are involved in the suppression of PAP1, PAP2, and MYB113 transcripts [31, 32]. Under specific physiological conditions (e.g., sugar accumulation or senescence), TAS4 and MYB genes are induced together, and TAS4 performs as an auto-regulatory factor to regulate anthocyanin production. MYB gene suppression by tasiRNA or siRNAs has also been reported in potatoes, sweet potatoes, and grapes [33-35].

Although the leaf is a major anthocyanin biosynthetic organ, anthocyanin accumulation in leaves produced at different stages of shoot has not yet been studied. Here, we describe how three R2R3-MYB factors are transcribed in juvenile and adult Arabidopsis leaves and characterize the role of TAS4 in MYB gene regulation.

\section{Results}

\section{Anthocyanin accumulation in different stage} of Arabidopsis leaves

To characterize the pattern of stress-induced anthocyanin production in leaves, the expression patterns of three anthocyanin transcription factors (PAP1, PAP2, and MYB113) were compared in leaves from different positions on the shoot. A nutrient-deficient condition is a strong inducer of anthocyanin synthesis [36], and a nitrogen deficient soil condition was prepared as described in the Methods section [37]. Arabidopsis Col-0 was grown at low nutrient soil to induce anthocyanin and leaves from different nodes were collected from 3-to 6-week-old plants. An image of 6-week-old plants (Fig. 1a) shows that leaves have more purple color on their abaxial than on their adaxial surface, and that leaves at higher nodes (from 5th to 12th leaves) have significantly more purple-colored pigments than leaves at lower nodes. Quantification of anthocyanin levels, which used water soluble extracts of red or purple pigments, in plants of different ages demonstrates that anthocyanin is uniformly expressed in the leaves of 3 and 4-week-old plants, but then increases to higher levels in apical leaves as plants age (Fig. 1b, c).

Three MYB gene expression levels were measured under normal growth conditions in leaves $1 / 2$ and 9/10 of 4-week-old plants (Fig. 1d). Under these conditions, PAP1 mRNA was more abundant than PAP2 and MYB113 mRNA, and PAP1 and PAP2 were more highly expressed in the $1 / 2$ leaves than in leaves $9 / 10$. Under nutrient-deficient conditions, these MYB genes were induced to different levels and in different temporal patterns in leaves $1 / 2$ and leaves $9 / 10$ (Fig. 1e-g). In leaves $1 / 2$, PAP1 was induced sevenfold in 23-day-old plants, and declined gradually over the next 19 days, whereas in leaves $9 / 10$ it was induced little, if at all, in 23-oldplants, and increased gradually in these leaves over the next 19 days (Fig. 1e). PAP2 was induced to much a much higher level than PAP1 in leaves 1/2 of 23-day-old plants, and increased transiently with leaf age before declining (Fig. 1f). It was expressed in a similar pattern, but at a much lower level, in leaves 9/10. MYB113 was expressed at much lower levels than PAP1 or PAP2 under both normal and nutrient-deficient conditions. Under nutrientdeficient conditions, MYB113 was expressed more highly in leaves $1 / 2$ than in leaves $9 / 10$ in 23-day-old plants, but this order was reversed as its expression declined in leaves $1 / 2$ and increased in leaves $9 / 10$ over the next 19 days. Consistent with this pattern TAS4, which negatively regulates MYB113 [36], increased in abundance in leaves $1 / 2$ from 23 to 42 days, although it was undetectable in leaves $9 / 10$ (Fig. 1h).

\section{TAS4 and miR828 reduce anthocyanin production under nutrient-deficient conditions}

Under normal growth conditions, we did not observe a major difference in the amount of anthocyanin in the TAS4 knock-out mutant (tas4ko) (SALK_066997) and the miR828 knock-out mutant (miR828ko) (SALK_021292) compared to wild-type plants. The only obvious difference was a slight increase in anthocyanin at the base of the petiole and in senescing leaves of tas4ko (Fig. 2a). Although the difference in

\footnotetext{
(See figure on next page.)

Fig. 1 Anthocyanin accumulation in Col-0 plant cultured on nutrient-deficient soil and short-day conditions. a The Arabidopsis leaf color changed in nutrient-deficient soils on the adaxial and abaxial sides. Scale bar indicates $1 \mathrm{~cm}$ in length. $\mathbf{b}$ Col-0 plants were grown for the indicated number of weeks under short-day conditions. Anthocyanin was quantified in different leaves from three to 6-week old plants. c More details of anthocyanin accumulations in the $1 \mathrm{st}$ and 2 nd and 9 th and 10 th leaves were measured and compared. The 9th and 10 th leaves at day 14 were omitted since they were not developed. * indicates a significant difference between leaves $1 / 2$ and 9/10 ( $n \geq 4, p<0.01)$. $\mathbf{d}$ Transcript level comparisons of three MYB genes in juvenile and adult leaves under normal plant growth conditions. Plants were grown for 4 weeks under normal long-day growth condition. * indicates a significant difference between leaves $1 / 2$ and $9 / 10(n \geq 3, p<0.01)$. e-h The expression patterns of three MYB genes and primary TAS4 transcription in the 1st and 2nd and 9th and 10th leaves under nutrient-deficient conditions. Each leaf was taken at day 14, 21, 29, and 42 after planting. * indicates significant difference in comparison with the other developmental stage of leaves $1 / 2$ or $9 / 10$ ( $n \geq 3, p<0.01$ ). RQ represents relative quantity of target genes
} 


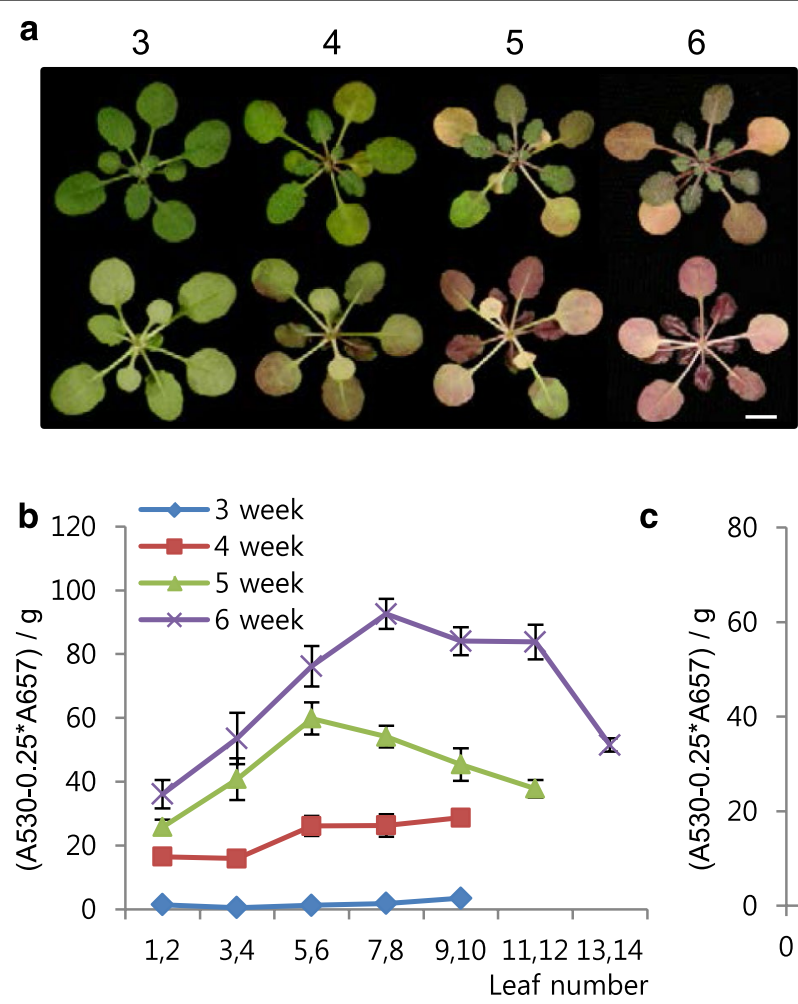

week

Adaxial

Abaxial
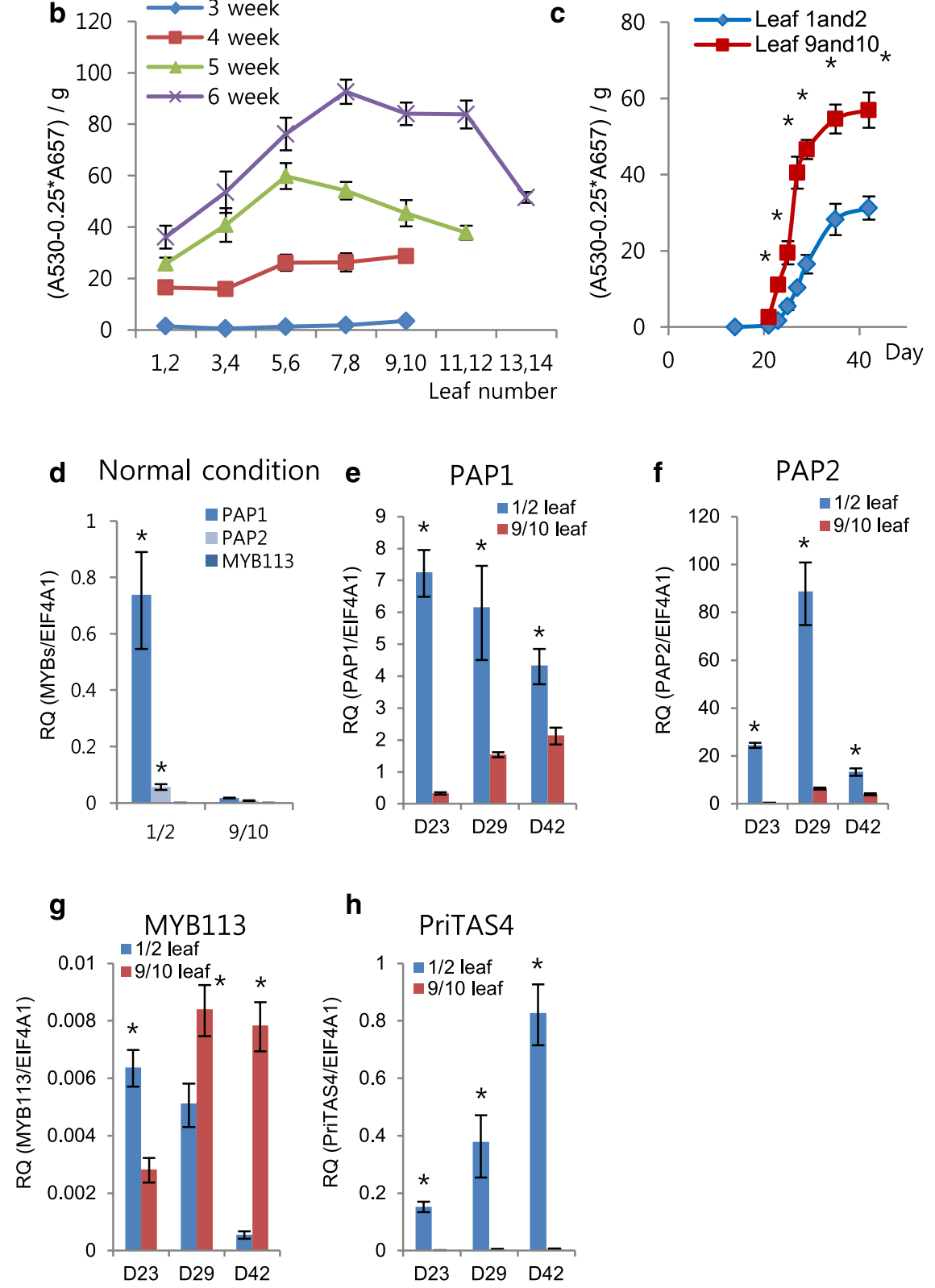

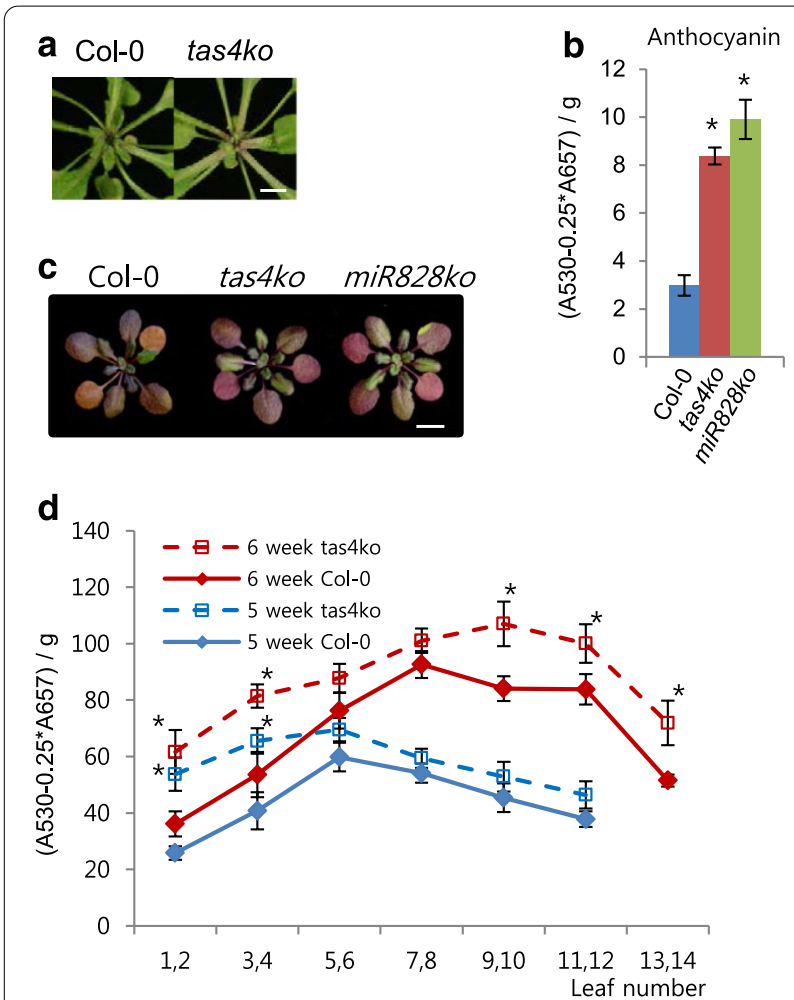

Fig. 2 Anthocyanin accumulation in the tas 4 ko and miR282ko mutants. a Color comparison of the base of leaves in Col-0 and tas 4 ko plants growing under the normal long-day growth condition. Scale bar indicates $1 \mathrm{~cm}$ in length. b Anthocyanin quantities in the whole plant of $\mathrm{Col}-0$ and tas $4 \mathrm{ko}$ and miR828ko mutants grown under normal conditions. At least three independent plants were tested for anthocyanin quantification. ${ }^{*}$ indicates a significant difference in comparison with Col-0 $(n \geq 3, p<0.01)$. c Leaf color changes in the tas4ko and miR828ko mutants. Every plant was cultured in nutrient-deficient soil for 6 weeks. Scale bar indicates $1 \mathrm{~cm}$ in length. $\mathbf{d}$ The anthocyanin accumulation patterns are compared for the different leaf stages in Col-0 and tas 4 ko mutant. * indicates a significant difference in comparison with Col-0 $(n \geq 4, p<0.01)$

the overall level of anthocyanin in mutant and wildtype plants is not clearly apparent (Fig. 2a), quantification of anthocyanin levels revealed that both mutants have approximately three-fold more anthocyanin than that of wild-type Col-0 (Fig. 2b). Therefore, to examine the effect of these genes on anthocyanin production in leaves, we grew the tas4ko and miR828ko in nutrient-deficient soil (Fig. 2c, d). We then compared the amount of anthocyanin in the tas $4 k o$ mutant and Col-0 in different leaves at 5 and 6 weeks after planting (Fig. 2d). In 5-week old plants, tas4ko had twice as much anthocyanin as Col-0 in leaves 1 to 4 , but had the same amount of anthocyanin as Col-0 in leaves 5 and above. In 6-week-old plants, anthocyanin was more abundant in every leaf of tas $4 k o$ relative to Col-0, although this difference was slightly greater in leaves 1-4 than in later leaves.

\section{TAS4 suppresses MYB genes primarily in juvenile leaves}

To explore the basis of the leaf-dependent TAS4 effect on anthocyanin production, we examined the effect of the tas $4 k o$ on the abundance of MYB gene transcripts in 5-week old Arabidopsis plants (Fig. 3). The PAP1 gene suppression by TAS4 was mainly observed in leaves $1 / 2$ (Fig. 3a). PAP2 gene suppression was mostly observed in juvenile stage leaves 1/4 (Fig. 3b). The PAP1 and PAP2 gene abundance in the juvenile leaves of tas $4 \mathrm{ko}$ is well explaining the anthocyanin abundance in leaves $1 / 4$ of tas4ko of 5-week-old plants (Fig. 2d). MYB113 transcription levels were greatly increased in leaves $9 / 12$ of tas4ko (Fig. 3c). The abundance of MYB113 transcript does not cause great difference of anthocyanin level in adult leaves of tas4ko (Figs. 2d and 3c). The level of the primary TAS4 transcript was high in the juvenile and transitional leaf stages and low in adult leaves (Fig. 3d). The PriTAS4 transcript pattern indicates that MYB gene suppression by TAS4 is stronger in juvenile leaves than in adult leaves and it explains well the suppression of PAP1 and PAP2 genes by TAS4 in juvenile leaves (Fig. 3a and b). The chlorophyll a/b-binding protein gene $(\mathrm{CAB})$ and senescence-associated gene 12 (SAG12) represent leaf senescence status similar to photosynthetic activity in the Col-0 and tas $4 k o$ plant (Fig. $3 \mathrm{e}$ and f). Slight differences were observed in the $\mathrm{CAB}$ and SAG12 gene expression level between Col-0 and tas $4 \mathrm{ko}$, but these physiological factors have no effect on MYB gene expression under experimental conditions.

\section{Discussion \\ Regulation of PAP1, PAP2, and MYB113 transcription in vegetative tissues}

PAP1, PAP2, and MYB113 genes were induced in nutrient-deficient, short-day conditions, but their expression patterns differed. PAP1 and PAP2 were expressed highly in juvenile leaves, but MYB113 was expressed higher in adult leaves (Figs. 1d and 3c). PAP1 and MYB113 expression was changed by plant aging too (Fig. 1e and g) and leaf aging causes the complexity of MYB gene expression patterns in vegetative leaves. PAP2 gene was inducible and expressed transiently (Fig. 1f). PAP2 gene expression was roughly 1000 times [i.e., relative quantities increased from 0.1 (Fig. 1f, D29 column) to 100 (Fig. 1d, PAP2 column)] under nutrient-deficient conditions when compared with that in normal growth conditions. This result indicates that PAP2 may play an important role in the regulation of anthocyanin accumulation in nutrient-deficient condition. 

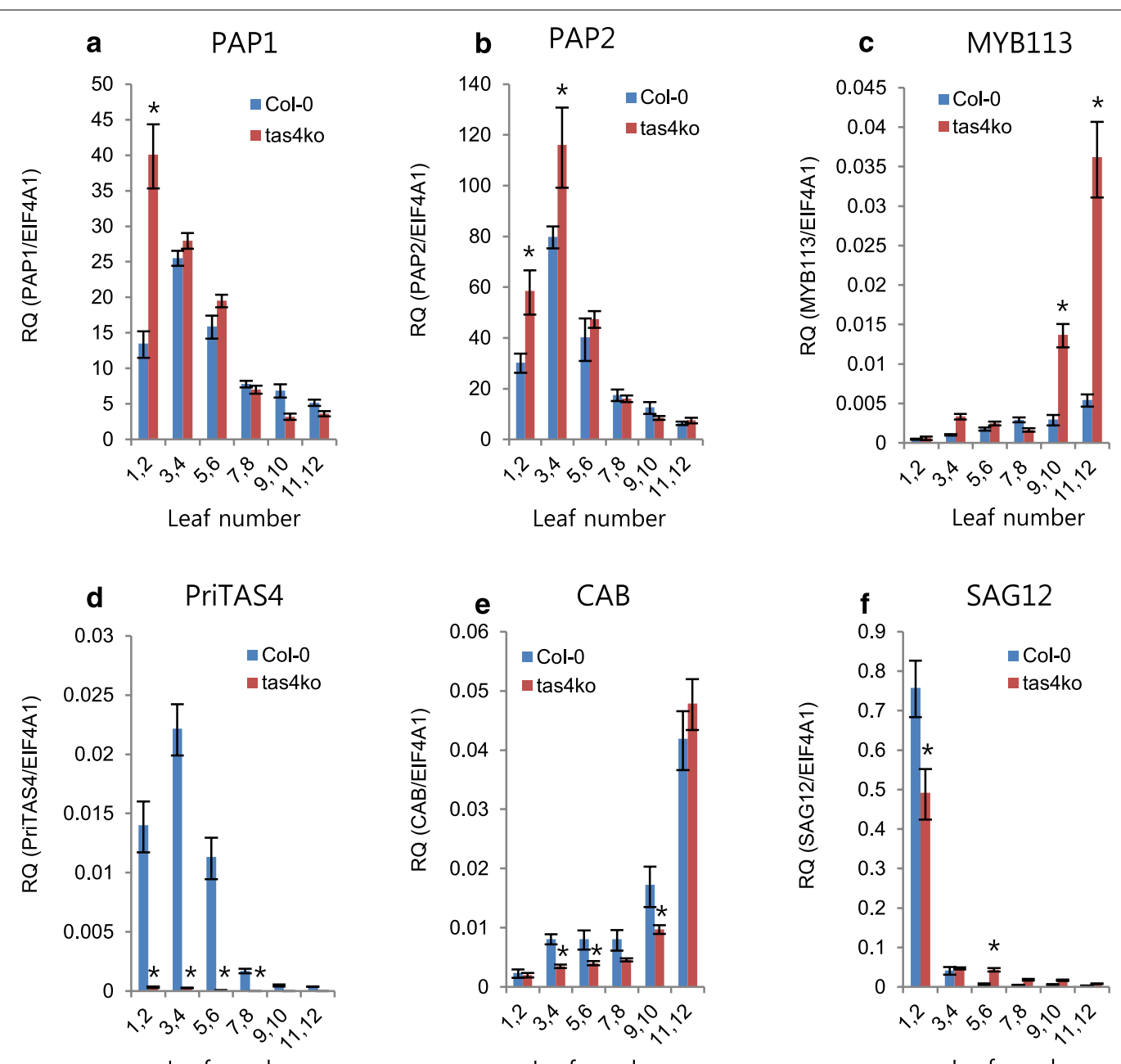

Fig. 3 The suppression of MYB gene transcription by TAS4 in the different leaves. a-d Three MYB genes and Pri-TAS4 levels were measured by qPCR. e, $\mathbf{f}$ The CAB2 and SAG12 transcription levels represented leaf senescence. * indicates a significant difference in comparison with Col-0 ( $n \geq 3$, $p<0.01)$. RQ represents relative quantity of target genes

\section{Suppression of PAP1, PAP2, and MYB113 transcript in vegetative tissues}

PAP1, PAP2, and MYB113 displayed different gene expression patterns during plant growth. PAP1 and PAP2 expressed relatively more in juvenile leaves than in adult leaves, but MYB113 expressed highly in adult leaves, which includes new developing leaves. The transcriptional repression was enhanced in the leaves where MYB factors were highly induced. The auto-regulatory loop of transcriptional induction of primary TAS4 is expected to reduce MYB gene expression during MYB gene induction $[32,36]$.

The transcriptional induction pattern of PAP1 and PAP2 is similar, but PAP2 was more inducible than PAP1 (Fig. 1d). The major transcriptional repression of PAP2 was shown in leaves $5 / 6$, rather than in leaves $1 / 4$, whereas PAP1 suppression was mostly shown in leaves $1 / 2$ (Fig. 3a and b). Since primary TAS4 expression was similar in leaves $1 / 2$ and in leaves $5 / 6$ (Fig. 3d), this site-specific suppression may be related to the expression levels of PAP1 and PAP2 and may also be the result of the different affinity of TAS4 to the PAP1 and PAP2 mRNA sequences.

\section{Methods}

\section{Plant materials and growth conditions}

Arabidopsis thaliana ecotype Col-0 plants were used for analysis. Plants were grown under long days $(16 \mathrm{~h}$ light/ $8 \mathrm{~h}$ dark) or short days ( $8 \mathrm{~h}$ light/16 $\mathrm{h}$ dark) with $95 \mu \mathrm{mol} \mathrm{m} \mathrm{m}^{-2} \mathrm{~s}^{-1}$ of light intensity using a 5:3 ratio of white (USHIO F32T8/741) and red-enriched (Interlectric F32/T8/WS Gro-Lite) fluorescent lights at $22{ }^{\circ} \mathrm{C}$ in Conviron growth chambers. Half of each pot was filled with soil (Fafard \#52 Mix of Sungro Horticultures, Agawam, MA), then the nutrients were leached using water 
10 times the volume of the soil. Arabidopsis was subsequently cultured without fertilizers. tas4 (salk_066997) and mir828 (salk_097788) were provided from the Arabidopsis stock center (ABRC, Columbus, $\mathrm{OH}$ ).

\section{Anthocyanin measurements}

Anthocyanin measurements followed the aforementioned method [11]. Briefly, $100 \mathrm{mg}$ of leaves were ground in liquid nitrogen and were extracted by adding Trizol reagent (Invitrogen, CA). Chlorophyll was eliminated successfully by extracting with chloroform. After separating the water phase, the organic phase was extracted once more with water to increase the recovery rate. The combined water extracts were measured with a spectrophotometer at A530 and A657 to quantify anthocyanin with the following equation: A530 - 0.25 × A657.

\section{Real-time qPCR}

RNA was extracted and reverse transcribed using SuperScript $^{\mathrm{TM}}$ II (Invitrogen, CA) and an 18-mer oligo(dT) primer. Quantified real-time assays were performed using Power SYBR Green PCR Master Mix (Applied Biosystems) and a StepOnePlusTM Real-Time PCR System (Applied Biosystems). A two-step protocol was followed: $20 \mathrm{~s}$ at the optimum melting temperature for each primer set and then $20 \mathrm{~s}$ at $72{ }^{\circ} \mathrm{C}$ for extension. Data were collected and analyzed using StepOne ${ }^{\mathrm{TM}}$ Software v2.0.1 (Applied Biosystems). Expression values relative to the internal control EIF4A1 (At3G13920) gene were calculated from the mean threshold curve $(\mathrm{Ct})$ value of three replicates. Melting curves and gel electrophoresis were used to verify the correct target amplifications. All primers used for reactions are provided in Table 1.

\section{Table 1 The oligo nucleotide sequences}

\begin{tabular}{ll}
\hline Oligo name & Sequence \\
\hline ElF4A-RTup & TTCAGATCCGAGTTTGGGAGATTCA \\
EIF4A-RTdn & CAGAAGGGGACGATTCCTCTTTGC \\
PAP1-RTup & CTGGGCTAAACCGGTCAGGAAAA \\
PAP1-RTdn & TGTAGGAATGGGCGTAATGTCTCT \\
PAP2-RTup & ACCAAGAAGCTGATGCGATTG \\
PAP2-RTdn & AACGTCAAACGCCAAAGTGG \\
MYB113-Rtup & CGAGTTCCTTTAAGAACTGGTCTCA \\
MYB113-RTdn & CAAGATCAACTTCATCGGAGCAGA \\
PriTAS4-RTup & GGTGAAGGACGAGCTGACTCTATA \\
PriTAS4-RTdn & CATCACTATTTAGGCAGTCAATGGTA \\
CAB2-RTup & GGTGGATGGTAGAGACTTTCAGATGT \\
CAB2-RTdn1 & ACAACGGAGTGAACCCAAGAACTGA \\
SAG12-RTup1 & CGAAGGCGGTTAATGGATACTGC \\
SAG12-RTdn1 & TTAACCGGGACATCCTCATAACCTG \\
\hline
\end{tabular}

Acknowledgements

Not applicable.

\section{Authors' contributions}

Conducting experiment: YK; Writing: YK, SP; Investigation: SP. Both authors read and approved the final manuscript.

\section{Funding}

Y.K. received funding from "Cooperative Research Program for Agriculture Science and Technology Development (Project No. PJ014776012020)," Rural Development Administration, Republic of Korea.

\section{Availability of data and materials}

The datasets used and/or analyzed during the current study are available from the corresponding author on reasonable request.

\section{Competing interests}

The authors declare that they have no competing interests.

\section{Author details}

${ }^{1}$ Department of Agricultural Chemistry, Chonnam National University, Gwangju 61186, South Korea. ${ }^{2}$ Department of Biology, University of Pennsylvania, Philadelphia 19104, USA.

Received: 29 November 2020 Accepted: 16 December 2020 Published online: 15 January 2021

\section{References}

1. Li J, Ou-Lee TM, Raba R, Amundson RG, Last RL (1993) Arabidopsis flavonoid mutants are hypersensitive to UV-B irradiation. Plant Cell 5(2):171-179

2. Harborne JB, Williams CA (2000) Advances in flavonoid research since 1992. Phytochemistry 55(6):481-504

3. Taylor LP, Grotewold E (2005) Flavonoids as developmental regulators. Curr Opin Plant Biol 8(3):317-323

4. Bais HP, Weir TL, Perry LG, Gilroy S, Vivanco JM (2006) The role of root exudates in rhizosphere interactions with plants and other organisms. Annu Rev Plant Biol 57:233-266

5. Peer WA, Murphy AS (2007) Flavonoids and auxin transport: modulators or regulators? Trends Plant Sci 12(12):556-563

6. Buer CS, Imin N, Djordjevic MA (2010) Flavonoids: new roles for old molecules. J Integr Plant Biol 52(1):98-111

7. Mol J, Grotewold E, Koes R (1998) How genes paint flowers and seeds. Trends Plant Sci 3(6):212-217

8. Williams RJ, Spencer JPE, Rice-Evans C (2004) Flavonoids: antioxidants or signalling molecules? Free Radic Biol Med 36(7):838-849

9. Garcia-Mediavilla V, Crespo I, Collado PS, Esteller A, Sánchez-Campos S, Tuñón MJ, González-Gallego J (2007) The anti-inflammatory flavones quercetin and kaempferol cause inhibition of inducible nitric oxide synthase, cyclooxygenase-2 and reactive C-protein, and down-regulation of the nuclear factor kappaB pathway in Chang Liver cells. Eur J Pharmacol 557(2-3):221-229

10. Misson J, Raghothama KG, Jain A, Jouhet J, Block MA, Bligny R et al (2005) A genome-wide transcriptional analysis using Arabidopsis thaliana Affymetrix gene chips determined plant responses to phosphate deprivation. Proc Natl Acad Sci USA 102(33):11934-11939

11. Teng S, Keurentjes J, Bentsink L, Koornneef M, Smeekens S (2005) Sucrose-specific induction of anthocyanin biosynthesis in Arabidopsis requires the MYB75/PAP1 gene. Plant Physiol 139(4):1840-1852

12. Solfanelli C, Poggi A, Loreti E, Alpi A, Perata P (2006) Sucrose-specific induction of the anthocyanin biosynthetic pathway in Arabidopsis. Plant Physiol 140(2):637-646

13. Devaiah BN, Karthikeyan AS, Raghothama KG (2007) WRKY75 transcription factor is a modulator of phosphate acquisition and root development in Arabidopsis. Plant Physiol 143(4):1789-1801

14. Feyissa DN, Løvdal T, Olsen KM, Slimestad R, Lillo C (2009) The endogenous $G L 3$, but not $E G L 3$, gene is necessary for anthocyanin accumulation 
as induced by nitrogen depletion in Arabidopsis rosette stage leaves. Planta 230(4):747-754

15. Olsen KM, Slimestad R, Lea US, Brede C, Løvdal T, Ruoff P, Verheul M, Lillo $C$ (2009) Temperature and nitrogen effects on regulators and products of the flavonoid pathway: experimental and kinetic model studies. Plant Cell Environ 32(3):286-299

16. Holton TA, Cornish EC (1995) Genetics and biochemistry of anthocyanin biosynthesis. Plant Cell 7(7):1071-1083

17. Winkel-Shirley B (2001) Flavonoid biosynthesis. A colorful model for genetics, biochemistry, cell biology, and biotechnology. Plant Physiol 126(2):485-493

18. Grotewold E (2006) The genetics and biochemistry of floral pigments. Ann Rev Plant Biol 57:761-780

19. Martin C, Prescott A, Mackay S, Bartlett J, Vrijlandt E (1991) Control of anthocyanin biosynthesis in flowers of Antirrhinum majus. Plant J 1(1):37-49

20. Quattrocchio F, Wing JF, Leppen H, Mol J, Koes RE (1993) Regulatory genes controlling anthocyanin pigmentation are functionally conserved among plant species and have distinct sets of target genes. Plant Cell 5(11):1497-1512

21. Shirley BW, Kubasek WL, Storz G, Bruggemann E, Koornneef M, Ausubel FM, Goodman HM (1995) Analysis of Arabidopsis mutants deficient in flavonoid biosynthesis. Plant J 8(5):659-671

22. Pelletier MK, Murrell JR, Shirley BW (1997) Characterization of flavonol synthase and leucoanthocyanidin dioxygenase genes in Arabidopsis. Further evidence for differential regulation of "early" and "late" genes. Plant Physiol 113(4):1437-1445

23. Pelletier MK, Shirley BW (1996) Analysis of flavanone 3-hydroxylase in Arabidopsis seedlings. Coordinate regulation with chalcone synthase and chalcone isomerase. Plant Physiol 111(1):339-345

24. Zhang F, Gonzalez A, Zhao M, Payne CT, Lloyd A (2003) A network of redundant bHLH proteins functions in all TTG1-dependent pathways of Arabidopsis. Development 130(20):4859-4869

25. Zimmermann IM, Heim MA, Weisshaar B, Uhrig JF (2004) Comprehensive identification of Arabidopsis thaliana MYB transcription factors interacting with R/B-like BHLH proteins. Plant J 40(1):22-34

26. Gonzalez A, Zhao M, Leavitt JM, Lloyd AM (2008) Regulation of the anthocyanin biosynthetic pathway by the TTG1/bHLH/Myb transcriptional complex in Arabidopsis seedlings. Plant J 53(5):814-827

27. Shi MZ, Xie DY (2014) Biosynthesis and metabolic engineering of anthocyanins in Arabidopsis thaliana. Recent Pat Biotechnol 8(1):47-60
28. Borevitz JO, Xia Y, Blount J, Dixon RA, Lamb C (2000) Activation tagging identifies a conserved MYB regulator of phenylpropanoid biosynthesis. Plant Cell 12(12):2383-2394

29. Stracke R, Werber M, Weisshaar B (2001) The R2R3-MYB gene family in Arabidopsis thaliana. Curr Opin Plant Biol 4(5):447-456

30. Tohge T, Nishiyama Y, Hirai MY, Yano M, Nakajima J, Awazuhara M, Inoue E, Takahashi H, Goodenowe DB, Kitayama M, Noji M, Yamazaki M, Saito K (2005) Functional genomics by integrated analysis of metabolome and transcriptome of Arabidopsis plants over-expressing an MYB transcription factor. Plant J 42(2):218-235

31. Rajagopalan R, Vaucheret $H$, Trejo J, Bartel DP (2006) A diverse and evolutionarily fluid set of microRNAs in Arabidopsis thaliana. Genes Dev 20(24):3407-3425

32. Hsieh LC, Lin SI, Shih AC, Chen JW, Lin WY, Tseng CY, Li WH, Chiou TJ (2009) Uncovering small RNA-mediated responses to phosphate deficiency in Arabidopsis by deep sequencing. Plant Physiol 151(4):2120-2132

33. Bonar N, Liney M, Zhang R, Austin C, Dessoly J, Davidson D, Stephens J, McDougall G, Taylor M, Bryan GJ, Hornyik C (2018) Potato miR828 is associated with purple tuber skin and flesh color. Front Plant Sci 9:1742

34. He L, Tang R, Shi X, Wang W, Cao Q, Liu X, Wang T, Sun Y, Zhang H, Li R, Jia $X$ (2019) Uncovering anthocyanin biosynthesis related microRNAs and their target genes by small RNA and degradome sequencing in tuberous roots of sweetpotato. BMC Plant Biol 19(1):232

35. Tirumalai V, Swetha C, Nair A, Pandit A, Shivaprasad PV (2019) miR828 and miR858 regulate $V V M Y B 114$ to promote anthocyanin and flavonol accumulation in grapes. J Exp Bot 70(18):4775-4792

36. Luo QJ, Mittal A, Jia F, Rock CD (2012) An autoregulatory feedback loop involving PAP1 and TAS4 in response to sugars in Arabidopsis. Plant Mol Biol 80(1):117-129

37. Smaling EMA, Fresco LO (1993) A decision-support model for monitoring nutrient balances under agricultural land use NUTMON. Geoderma 60(1-4):235-256

\section{Publisher's Note}

Springer Nature remains neutral with regard to jurisdictional claims in published maps and institutional affiliations.

\section{Submit your manuscript to a SpringerOpen ${ }^{\circ}$ journal and benefit from:}

- Convenient online submission

- Rigorous peer review

- Open access: articles freely available online

- High visibility within the field

- Retaining the copyright to your article

Submit your next manuscript at springeropen.com 